\title{
SYMBIOTIC GERMINATION OF THREATENED AUSTRALIAN TERRESTRIAL ORCHIDS AND THE EFFECT OF NURSERY POTTING MEDIA ON SEEDLING SURVIVAL
}

\author{
Magali Wright $^{1,3,4}$, Zoe SMith ${ }^{1,3}$, Richard Thomson $^{2} \&$ Rob Cross $^{3}$ \\ ${ }^{1}$ School of Resource Management, Burnley Campus, The University of Melbourne, 500 Yarra Boulevard \\ Richmond, Victoria, 3121, Australia \\ ${ }^{2}$ Australasian Native Orchid Society [ Victorian Group], PO Box 354, Glen Waverley, Victoria, 3150, Australia \\ ${ }^{3}$ Royal Botanic Gardens Melbourne, Birdwood Avenue, South Yarra, Victoria, 3141, Australia \\ ${ }^{4}$ Author for correspondence: m.wright2@pgrad.unimelb.edu.au
}

KEY WORDS: symbiotic propagation, endangered orchids, potting media

\section{The ex situ propagation program at the Royal Botanic Gardens, Melbourne (RBG)}

Since the early 1990s, the RBG has contributed to the conservation of Victoria's Endangered orchids through its ex situ propagation program. Working cooperatively with the Victorian Department of Sustainability and Environment (DSE), the Melbourne Zoo, the Australasian Native Orchid Society, The University of Melbourne, RMIT University and Parks Victoria, research and development has lead to a greater understanding of Victoria's terrestrial orchids and their associated mycorrhizal fungi, and assisted in the implementation of Recovery Plans. Victoria has high orchid biodiversity, with nearly a quarter of Australia's 1250 species occurring in only 3\% percent of the land area. Many of Victoria's orchid species are under threat of extinction, and with nearly $40 \%$ endemism (Backhouse and Cameron 2005) this is of national and even global concern.

The aim of the ex situ propagation program at the RBG is to provide symbiotically grown orchids for reintroduction into natural habitats. Plants are also being propagated to establish ex situ populations of species that are under high risk of extinction. Ex situ populations provide seed orchards that decrease the pressure of seed collection on threatened wild populations. Currently, for over 45 threatened orchid species from the genera Caladenia, Diuris, Thelymitra, Paracaleana, Prasophyllum, Pterostylis, Calochilus and Corunastylis, isolation of mycorrhizal fungi and symbiotic germination of seed are being attempted.
To date, these techniques have been successful for 27 species belonging to the genera Caladenia, Diuris, Thelymitra and Pterostylis. Laboratory-grown seedlings from these genera have been acclimatised to the nursery environment. The step involving seedling transfer to nursery media has regularly resulted in seedling losses, being particularly noticeable after the first dormancy period. Apart from providing appropriate environmental conditions such as humidity, light and aeration, the design of the nursery-potting medium was considered to be of importance to ensure that adequate moisture levels are maintained with minimal risk of tuber death in overly wet substrates.

\section{Potting media}

The effect of four different nursery media on seedling survival was investigated for a range of species from the genera Caladenia, Diuris, Thelymitra and Pterostylis and their emergence after summer dormancy was recorded. The potting media used included: the RBG cutting mix, the Australasian Native Orchid Society (ANOS) mix, a Zoo mix equivalent and our own pine-bark based mix. The RBG cutting mix is a highly aerated gravel based mix routinely used at the in RBG nursery for propagating plants from cuttings. The ANOS mix was developed for the cultivation of Australian terrestrial orchids and is high in naturally occurring organic matter including bark, leaf mould and litter. The Zoo mix is used by the Melbourne Zoo in their ex situ terrestrial orchid collection and our equivalent comprises of a 
1:1 ratio of perlite and a Debco potting mix (composted pine bark). Our pine-bark based mix contained the Debco potting mix with the course and fine particles removed by sieving, which was mixed three parts to one part perlite.

All species were germinated with mycorrhizal fungi isolated from the same population as the seed was collected from, according to methods described by Clements et al. (1986). In 2005 symbiotically germinated seedlings were transferred into these four mixes in Hykos ${ }^{\circledR}$ ( 40 celled trays). As seedlings were being grown primarily for conservation purposes they were transferred after reaching a size where ex vitro survival was deemed possible. This meant that the sample size of the different species varied and all species were transferred over a number of months. Those species with sufficient sample sizes to compare their survival in all four media were from the genera Caladenia and Diuris and included: C. amoena D.L. Jones, C. calcicola G.W. Carr, C. cruciformis D.L. Jones, C. robinsonii G.W. Carr, C. versicolor G.W. Carr, C. xanthochila D. Beardsell \& C. Beardsell, D. fragrantissima D.L. Jones \& M.A. Clem. and D. sp. aff. chryseopsis (Basalt Plains) sensu Ross \& Walsh (2003).

\section{Survival results}

The survival (emergence after summer dormancy) of these species was recorded in July 2006. All of the Caladenia species had their highest survival in either the Zoo mix equivalent or our pine-bark based mix and many had little or no survival in the ANOS and RBG cutting mixes. Two species had reasonable survival in all four mixes, C. xanthochila (with more than $50 \%$ ) and C. calcicola (with more than 30\%). Overall the Diuris species had lower survival than the Caladenia species. These results are unusual as Caladenia species are generally recognised to be more difficult to grow than Diuris species (Richards et al. 1984). The Diuris species had similar survival in the Zoo equivalent mix, our pine-bark based mix and RBG cutting mix (15-30\%). Their survival in the ANOS mix differed, as the highest survival for $D$. sp. aff. chryseopsis $(40 \%)$ was observed in this mix and the lowest for $D$. fragrantissima $(7 \%)$. D. sp. aff. chryseopsis was the only species of the eight tested to achieve highest survival rates in the ANOS mix. The low survival of the Diuris species is unlikely to be due to the range of potting mixes used. The Zoo mix is primarily used for the transferal of asymbiotically germinated $D$. fragrantissima seedlings at the Melbourne Zoo ex situ collection. These plants are transferred to potting media after tuber formation, at approximately 18-months old, and survival rates of up to $90 \%$ are regularly observed ( $\mathrm{R}$. Thomson pers. obs. 2006). The smaller size of the symbiotic Diuris seedlings transferred in 2005 may have lead to below average survival. In 2006, we grew Diuris seedling in the in vitro environment until they were larger before transferal to the nursery environment. Both Pterostylis and Thelymitra species transferred into the Zoo mix equivalent and our pine-bark based mix survived the summer dormancy. These mixes appeared to be the most appropriate mixes for the range of species and genera tested.

\section{Implications for potting mix selection}

Survival results for the Caladenia and Diuris species lead to the selection of the Zoo mix equivalent and our pine-bark based mix for the use in further transferal of symbiotic seedlings. These two mixes where used exclusively in seedling transferals conducted during 2006. In addition to providing maximum plant survival rates, the mixes are both replicable; as both the Debco potting mix and the perlite used in these mixes are quality tested and conform to Australian Standards. The lack of replicable components in the ANOS mix may explain why many of the species tested had such low survival in this mix when it is routinely used with success by ANOS members. The ANOS mix has several components collected from the natural environment and these components differ depending on where they are collected. The mix we used was quite dry and water repellent. It is possible that if we used an ANOS mix made with components from a different source we would have observed different results.

\section{Overall program outcome}

The RBG's ex situ propagation program has produced hundreds of plants of a number of endangered species for reintroduction and ex situ collections. 
Some of these plants have larger leaves than adult plants of the same species observed in the field. Many Caladenia species flowered in the nursery 18 months after germination including C. amoena, C. xanthochila, C. hastata, C. calcicola and C. robinsonii. Reintroductions of two Pterostylis species propagated were undertaken by DSE staff in 2006. The majority of remaining plants will be grown on in the nursery and reintroduction conducted when climatic conditions are conducive to survival in situ.

ACKNOWLEDGMENTS. We would like to acknowledge Chris Jenek of the RBG nursery for looking after the terrestrial orchid plants and seedlings. We would also like to acknowledge the generous funding of the DSE. The fund- ing of the Australian Orchid Foundation, the E.A. Crespin Scholarship, the J.M. Higgins Research Foundation and the Melbourne Abroad Travelling Scholarships made it possible for two of the authors to be present at this congress.

\section{LiteratuRE Cited}

Backhouse, G. \& D. Cameron. 2005. Application of the IUCN 2001 Red List categories in determining the conservation status of native orchids of Victoria, Australia. Selbyana 26: 55-74.

Clements, M., P.J. Cribb \& H. Muir. 1986. A preliminary report on the symbiotic germination of European terrestrial orchids. Kew Bull. 14: 437-445.

Richards, H., R. Wotton \& R. Datodi. 1984. In: Cultivation of Australian native orchids. Australian Native Orchid Society Victoria Group Inc.

Magali Wright is a PhD student at the University of Melbourne studying use of mycorrhizal fungi in re-introduction of Caladenia species. She also works at the Royal Botanic Gardens, Melbourne, as an orchid conservation officer.

Zoe Smith received her $\mathrm{PhD}$ from the University of Melbourne in the field of orchid conservation. She worked at the Royal Botanic Gardens, Melbourne, as and orchid conservation officer from 2004 to 2006. She is currently an environmental consultant.

Richard Thomson is a member of Australian Native Orchid Society Victoria Group. He volunteers at the RBG bringing his wide knowledge of native orchid propagation and cultivation.

Rob Cross supervises the ex situ component of the Recovery Plans for Endangered Victorian orchids at the Royal Botanic Gardens, Melbourne in association with the Department of Sustainability and Environment (DSE). 